\title{
Synthesis and pharmacological evaluation of coumarins as new scaffold on the Parkinson's disease
}

\author{
Maria Joao Matos,,${ }^{\mathrm{a},}$ Dolores Viña, ${ }^{\mathrm{b}}$ Patricia Janeiro, ${ }^{\mathrm{a}}$ Francisco Orallo, ${ }^{\mathrm{b}}$ Eugenio Uriarte ${ }^{\mathrm{a}}$ and Lourdes \\ Santana $a^{a}$ \\ ${ }^{\mathrm{a}}$ Department of Organic Chemistry and ${ }^{\mathrm{b}}$ Department of Pharmacology, Faculty of Pharmacy, University \\ of Santiago de Compostela 15782, Spain.
}

\begin{abstract}
"Abstract." With the aim to find out the structural features for the MAO inhibitory activity and selectivity, in the present communication we report the design, synthesis and pharmacological evaluation of a new series of 8-bromo-6-methyl-3-phenylcoumarin derivatives without substituent and with different number of methoxy substituent in the 3-phenyl ring. The substituent in this new scaffold was introduced in the 3', 4' and/or 5' positions of the 3-phenyl ring of the coumarin moiety. The synthesized compounds 3-6 were evaluated as MAO A and B inhibitors using R-(-)-deprenyl (selegiline) and Iproniazide as reference inhibitors, showing, most of them, MAO-B inhibitory activities in the nanomolar range. Compounds $3(11.05 \pm 0.81 \mathrm{nM}), 4(3.23 \pm 0.49 \mathrm{nM})$ and $\mathbf{5}(7.12 \pm 0.01$ $\mathrm{nM}$ ) show higher activity than selegiline $\left(\mathrm{IC}_{50}=19.60 \mathrm{nM}\right)$, and high MAO-B selectivity with 9,050fold, 30,960-fold and 14,045-fold inhibition levels, with respect to the MAO-A isoform.
\end{abstract}

*To whom correspondence should be addressed - e-mail: mariajoao.correiapinto@rai.usc.es

\section{Introduction}

Coumarins (or benzopyrones) are a large family of compounds, of natural and synthetic origin, that show numerous biological activities. ${ }^{1}$ Recent studies pay special attention to their antioxidative, anticarcinogenic and enzymatic inhibition properties. ${ }^{2,3,4,5,6}$ In regard to the monoamine oxidase (MAO) inhibition, ${ }^{7,8}$ the recent findings revealed that MAO-A and MAO-B affinity and selectivity can be efficiently modulated by appropriate substitutions in the coumarin ring, in particular in the $3 / 4$ and $6 / 7$ 
positions. $^{9,10,11,12,13}$

On the other hand, the resveratrol, (3,4',5-trihydroxystilbene), is a natural polyphenolic compound present in grapes and red wine, which possesses a variety of biological activities including antiinflammatory, antioxidant, anticancer and cardioprotective properties and enzyme inhibition. $^{14,15,16,17,18,19}$

Due to that, this compound has attracted much interest in the past decade, and recently it has been demonstrated that resveratrol also is proved to be MAO inhibitory activity. ${ }^{15,20}$

Mono amine oxidases (MAOs) are flavoenzymes bound to the outer mitochondrial membrane and are responsible for the oxidative deamination of neurotransmitters and dietary amines. ${ }^{21,22}$ Two isoforms, namely MAO-A and MAO-B, have been identified on the basis of their amino acid sequences, three-dimensional structure, substrate preference and inhibitor selectivity ${ }^{23,24} \mathrm{MAO}-\mathrm{A}$ has a higher affinity for serotonin and noradrenaline whereas MAO-B preferentially deaminates phenylethylamine and benzylamine. ${ }^{25}$ These properties determine the clinical importance of MAO inhibitors. Selective MAO-A inhibitors such as clorgyline (irreversible) and moclobemide (reversible) are used in the treatment of neurological disorders such as depression, ${ }^{26,27}$ whereas the selective and irreversible MAOB inhibitors such as selegiline and rasagiline are useful in the treatment of Parkinson's ${ }^{28,29}$ and Alzheimer's diseases. ${ }^{30,31}$

In this context, and in an attempt to develop novel MAO-B selective inhibitors, we have previously synthesized 3-aryl coumarin derivatives in which are present both, the coumarin and the resveratroltemplates, compounds that have show very high MAO-B inhibitory activity and selectivity. ${ }^{7,8}$ In the present work, a variety of substituents with different size and lipophilicity were introduced in both aromatic rings and the new compounds were evaluated as MAO inhibitors. 


\section{Results and discussion}

In the present work we designed and evaluated a series of 8-bromo-6-methyl-3-phenylcoumarin derivatives with different number of methoxy substituent in the 3-phenyl ring. The compounds were synthesized according to Scheme 1 and details are given in the Experimental section.

The prepared series of compounds proved to be selective inhibitors of the MAO-B isoenzyme. The compound 4, with one methoxy substituent in the phenyl ring, is by itself very active and selective to MAO-B isoenzyme. Compounds $\mathbf{3}$ and $\mathbf{5}$ (without any substituent and with two methoxy groups) have a MAO-B $I C_{50}$ on the same activity range. This three compounds have similar inhibitory activity of the R(-)-deprenyl (reference MAO-B inhibitor) and are much more selective than this one. The most potent molecule of this family is the compound 4 , with one methoxy group in 4' position $\left(I C_{50}=3.23 \pm 0.49\right.$ $\mathrm{nM})$. This one is six times more active and several times more selective iMAO-B than the R-(-)deprenyl. Compound 6, with 3-methoxy groups, loses activity (activity on the micromolar range) and selectivity in respect to the mono and dimethoxy derivatives (compounds $\mathbf{4}$ and $\mathbf{5}$, respectively). Compounds 3-5 don't present MAO-A inhibitory activity for the highest concentration tested (100 $\mu \mathrm{M})$. This iMAO-B selectivity is an important factor to discriminate the potential therapeutic application of this kind of molecules.

Comparing the iMAO-B activities of $\mathbf{3}$ and $\mathbf{4}$, the introduction of one methoxy substituent in 4' position of the molecule increases the inhibitory activity. When the phenyl ring is substituted with two methoxy groups in the 3' and 5'positions, compound 5, the iMAO-B activity is even better than the nonsubstituted. When the number of methoxy substituent increases to three, compound $\mathbf{6}$, it decreases the enzymatic inhibitory activity to the micromolar range, and the compound loses the selectivity. The presence of methoxy substituent in the 3-phenyl ring seems to be important to modulate and improve the inhibitory enzymatic activity of the 6-methyl-3-phenylcoumarins. 
The inhibitory MAO activity of compounds 3-6 was evaluated in vitro by the measurement of the enzymatic activity of human recombinant MAO isoforms in BTI insect cells infected with baculovirus. ${ }^{7,8,32}$ Then, the $I C_{50}$ values and MAO-B selectivity ratios $\left[I C_{50}\right.$ (MAO-A)]/[IC 50 (MAO-B)] for inhibitory effects of both new compounds and reference inhibitors were calculated (table 1). ${ }^{33}$

Table 1. MAO-A and MAO-B inhibitory activity results for compounds 3-6 and reference compounds.

\begin{tabular}{cccc}
\hline Compounds & MAO-A & MAO-B & Ratio \\
& $\mathrm{IC}_{50}$ & $\mathrm{IC}_{50}$ & \\
\hline $\mathbf{3}$ & $*$ & $11.05 \pm 0.81 \mathrm{nM}$ & $>9,050^{\mathrm{b}}$ \\
$\mathbf{4}$ & $*$ & $3.23 \pm 0.49 \mathrm{nM}$ & $>30,960^{\mathrm{b}}$ \\
$\mathbf{5}$ & $*$ & $7.12 \pm 0.01 \mathrm{nM}$ & $>14,045^{\mathrm{b}}$ \\
$\mathbf{6}$ & $31.20 \pm 2.09 \mu \mathrm{M}$ & $4.89 \pm 0.22 \mu \mathrm{M}$ & 6.4 \\
R-(-)-deprenyl & $67.25 \pm 1.02 \mu \mathrm{M}^{\mathrm{a}}$ & $19.60 \pm 0.86 \mathrm{nM}$ & 3,431 \\
Iproniazide & $6.56 \pm 0.76 \mu \mathrm{M}$ & $7.54 \pm 0.36 \mu \mathrm{M}$ & 0.87 \\
\hline
\end{tabular}

*Inactive at $100 \mu \mathrm{M}$ (highest concentration tested). At higher concentrations the compounds precipitate. ${ }^{\mathrm{a}} P<0.01$ versus the corresponding $I C_{50}$ values obtained against MAO-B, as determined by ANOVA/Dunnett's.

${ }^{\mathrm{b}}$ Values obtained under the assumption that the corresponding $I C_{50}$ against MAO-A is the highest concentration tested $(100 \mu \mathrm{M})$.

Chemistry. The coumarin derivatives 3-6 were efficiently synthesized according to the synthetic protocol outlined in Scheme 1.

The treatment of the precursor 1 with $\mathrm{N}$-bromosuccinimide (NBS) under reflux of $\mathrm{CCl}_{4}$, using 2,2'azo-bis-iso-butyronitrile (AIBN) as catalyst, afforded the bromo derivative $\mathbf{2}$ with a yield of $44 \%$. The 
obtained product is purified by flash chromatography, using a mixture of hexane/ethyl acetate, in a proportion 95:5, as eluent. The most activated position on the compound $\mathbf{1}$ is the ortho in respect to the hydroxyl substituent and the bromination occurs there. So, the bromination on the reactive $\mathbf{1}$ allows discriminating the position of the bromo atom on the final coumarin's benzenic ring.

The preparation of these 8-bromo-6-methyl-3-phenylcoumarins was performed via the classical Perkin reaction. $^{7,8,34,35,36}$ This reaction occurs by condensation of the 3-bromo-5-methylsalicylaldehyde 2 and the conveniently substituted phenylacetic acids, with $N, N^{\prime}$-dicyclohexylcarbodiimide (DCC) as dehydrating agent, in reflux of DMSO, during 24 hours (scheme 1). The reaction to obtain 3-6 is very clean and the yields are between $45-50 \% .^{30-33}$ The obtained products are easy to purify by flash chromatography, using a mixture of hexane/ethyl acetate in a proportion 9:1 as eluent.

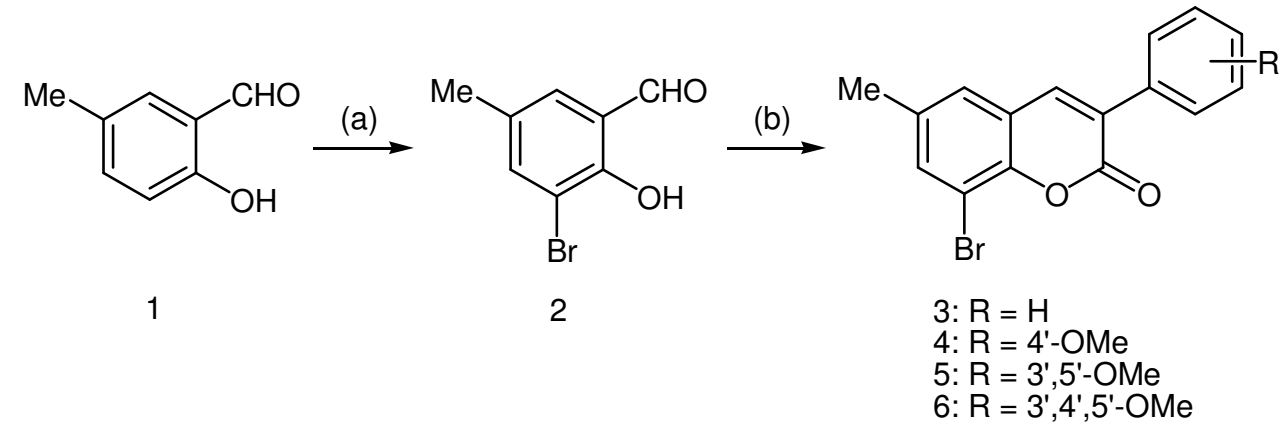

Scheme 1. Synthetic strategy for the prepared compounds. (a) NBS, AIBN, $\mathrm{CCl}_{4}$, reflux, $18 \mathrm{~h}$ (b) phenylacetic acids, DCC, DMSO, $110^{\circ} \mathrm{C}, 24 \mathrm{~h}$.

MAO inhibition assay. The potential effects of the test drugs on hMAO activity were investigated by measuring their effects on the production of hydrogen peroxide from $p$-tyramine (a common substrate for both hMAO-A and hMAO-B), using the 10-acetyl-3,7-dihydroxyphenoxazine as reagent and microsomal MAO isoforms prepared from insect cells (BTI-TN-5B1-4) infected with recombinant baculovirus containing cDNA inserts for hMAO-A or hMAO-B. 
The production of $\mathrm{H}_{2} \mathrm{O}_{2}$ catalyzed by $\mathrm{MAO}$ isoforms can be detected using the previously mentioned reagent, a non-fluorescent, highly sensitive and stable probe that reacts with $\mathrm{H}_{2} \mathrm{O}_{2}$ in the presence of horseradish peroxidase to produce a fluorescent product: resorufin. In this study hMAO activity was evaluated using the above method following the general procedure described previously by us. ${ }^{37,38}$

The tested drugs (new compounds and reference inhibitors) inhibited the control enzymatic MAO activities and the inhibition was concentration dependent. The corresponding $I C_{50}$ values and MAO-B selectivity ratios $\left[I C_{50}(\mathrm{MAO}-\mathrm{A})\right] /\left[I C_{50}(\mathrm{MAO}-\mathrm{B})\right]$ are shown in Table $\mathbf{1 .}$

\section{Conclusions}

These hybrid compounds with resveratrol-coumarin skeleton show high selectivity to MAO-B isoenzyme and activity in the nanomolar range. We had prepared new coumarin derivatives with inhibitory activity comparable to those of selegiline, which is used as reference inhibitors and has a very high MAO-B selectivity. Introduction of one or two methoxy groups in the phenyl ring improves the activity, giving more active and selective compounds than the reference ones. These findings have encouraged us to continue our investigations into the design of more potent and selective analogs by introducing appropriate substituent into the coumarin scaffold, potential medicines for the Parkinson's disease. These modifications, which we studying more deeply, can improve the pharmacologic profile of the synthesized coumarins.

\section{Experimental section}

Chemistry. Melting points were determined using a Reichert Kofler thermopan or in capillary tubes on a Büchi 510 apparatus and are uncorrected. ${ }^{1} \mathrm{H}$ NMR spectra were recorded on a Bruker AMX spectrometer at 300 and $75.47 \mathrm{MHz}$, respectively, using TMS as internal standard (chemical shifts in values, $J$ in Hz). Silica gel (Merck 60, 230-00 mesh) was used for flash chromatography (FC). 
Analytical thin layer chromatography (TLC) was performed on plates precoated with silica gel (Merck $60 \mathrm{~F} 254,0.25 \mathrm{~mm})$.

General procedure for the preparation of 3-bromo-2-hydroxy-5-methylbenzaldehyde (2). A solution of $1(0.8 \mathrm{~g}, 5.88 \mathrm{mmol})$, NBS $(1.25 \mathrm{~g}, 7.05 \mathrm{mmol})$ and a catalytic quantity of $\mathrm{AIBN}$ in $\mathrm{CCl}_{4}$ was stirred under reflux for $18 \mathrm{~h}$. The result solution was filtered to remove the succinimide. The solvent was evaporated under vacuum and purified by FC (hexane/ethyl acetate $95: 5)$ to give $2(0.73 \mathrm{~g}, 58 \%)$ as a white solid. Mp 64-5 ${ }^{\circ} \mathrm{C}$ (biblio. $\left.64-6{ }^{\circ} \mathrm{C}\right) .{ }^{1} \mathrm{H}$ NMR $\left(\mathrm{CDCl}_{3}\right) \delta(\mathrm{ppm}), J(\mathrm{~Hz}): 2,34\left(\mathrm{~s}, 3 \mathrm{H},-\mathrm{CH}_{3}\right), 7,33$ (d, 1H, H-4, J=2.0), 7,62 (d, 1H, H-6, J=2.0), 9,81 (s, 1H, -CHO).

General procedure for the preparation of 8-bromo-6-methylcoumarins (3-6). A solution of 3bromo-2-hydroxy-6-methylbenzalhehyde $(2,0.12 \mathrm{~g}, 0.56 \mathrm{mmol})$ and phenylacetic acid $(0.095 \mathrm{~g}, 0.70$ $\mathrm{mmol})$ in DMSO and DCC $(0.18 \mathrm{~g}, 0.87 \mathrm{mmol})$ was heated in an oil-bath at $100-110{ }^{\circ} \mathrm{C}$ for $24 \mathrm{~h}$. Triturate ice $(20 \mathrm{~mL})$ and acetic acid $(3.0 \mathrm{~mL})$ were added to the reaction mixture. After keeping it at room temperature for $2 \mathrm{~h}$, the mixture was extracted with ether $(3 \mathrm{x} 25 \mathrm{~mL})$. The organic layer was extracted with sodium bicarbonate solution $(50 \mathrm{~mL}, 5 \%)$ and then water $(20 \mathrm{~mL})$. The solvent was evaporated under vacuum and the dry residue was purified by FC (hexane/ethyl acetate 9:1) to give $\mathbf{3}$ $(0.06 \mathrm{~g}, 45 \%)$ as a white solid. $\mathrm{Mp} 144-5{ }^{\circ} \mathrm{C} .{ }^{1} \mathrm{H} \mathrm{NMR}\left(\mathrm{CDCl}_{3}\right) \delta(\mathrm{ppm}), J(\mathrm{~Hz}): 2,41\left(\mathrm{~s}, 3 \mathrm{H},-\mathrm{CH}_{3}\right), 3,86$ (s, 3H, $-\mathrm{OCH}_{3}$ ), 6,98 (d, 2H, H-3' and H-5', J=7.1), 7,26 (s, 1H, H-7), 7,56 (s, 1H, H-5), 7,65-7,69 (m, 3H, H-2', H-6' and H-4).

8-Bromo-6-methyl-3(4'-methoxyphenyl)coumarin (4). Yield: $47 \%$. Mp: $144-5{ }^{\circ} \mathrm{C} .{ }^{1} \mathrm{H}$ NMR $\left(\mathrm{CDCl}_{3}\right)$ $\delta(\mathrm{ppm}), J(\mathrm{~Hz}): 2.40\left(\mathrm{~s}, 3 \mathrm{H},-\mathrm{CH}_{3}\right), 3.87\left(\mathrm{~s}, 3 \mathrm{H},-\mathrm{OCH}_{3}\right), 6.98\left(\mathrm{~d}, 2 \mathrm{H}, \mathrm{H}-3^{\prime}, \mathrm{H}-5\right.$ ', J=7.10), $7.26(\mathrm{~s}, 1 \mathrm{H}$, H-7), 7.56 (s, 1H, H-5), 7.67 (dd, 3H, H-4, H-2', H-6', J=6.93 and $J=1.08$ ).

8-Bromo-6-methyl-3(3',5'-dimethoxyphenyl)coumarin (5). Yield: $46 \%$. Mp: $165-6{ }^{\circ} \mathrm{C} .{ }^{1} \mathrm{H}$ NMR $\left(\mathrm{CDCl}_{3}\right) \delta(\mathrm{ppm}), J(\mathrm{~Hz}): 2.40\left(\mathrm{~s}, 3 \mathrm{H},-\mathrm{CH}_{3}\right), 3.83\left(\mathrm{~s}, 6 \mathrm{H},\left(-\mathrm{OCH}_{3}\right)_{2}\right), 6.51\left(\mathrm{t}, 1 \mathrm{H}, \mathrm{H}-4^{\prime} J=2.26\right), 6.83(\mathrm{~d}$, 2H, H-2', H-6', J=2.27), 7.26 (s, 1H, H-7), 7.57 (s, 1H, H-5), 7.70 (s, 1H, H-4). 
8-Bromo-6-methyl-3(3',4',5'-trimethoxyphenyl)coumarin (6). Yield: 50\%. Mp: $167-8{ }^{\circ} \mathrm{C} .{ }^{1} \mathrm{H}$ NMR $\left(\mathrm{CDCl}_{3}\right) \delta(\mathrm{ppm}), J(\mathrm{~Hz}): 2.41\left(\mathrm{~s}, 3 \mathrm{H},-\mathrm{CH}_{3}\right), 3.91\left(\mathrm{~d}, 9 \mathrm{H},\left(-\mathrm{OCH}_{3}\right)_{3}, J=5.75\right), 6.92(\mathrm{~s}, 2 \mathrm{H}, \mathrm{H}-2$ ', H-6'), 7.28 (d, 1H, H-7, J=6.5), 7.59 (d, 1H, H-5, J=1.3), 7.70 (s, 1H, H-4).

Biological assay. Enzymatic MAO-A and MAO-B activity of compounds was determined by a fluorimetric method following a previously described protocol ${ }^{39}$ Briefly, $0.1 \mathrm{~mL}$ of sodium phosphate buffer $(0.05 \mathrm{M}, \mathrm{pH} 7.4)$ containing various concentrations of the test drugs and appropriate amounts of recombinant hMAO-A or hMAO-B and adjusted to obtain in our experimental conditions the same reaction velocity in the presence of both isoforms were incubated for $15 \mathrm{~min}$ at $37^{\circ} \mathrm{C}$ in a flat-blackbottom 96-well microtest plate placed in the dark fluorimeter chamber. After this incubation period, the reaction was started by adding (final concentrations) $200 \mu \mathrm{M}$ of 10-acetyl-3,7-dihydroxyphenoxazine reagent (Amplex Red assay kit), $1 \mathrm{U} / \mathrm{ml}$ horseradish peroxidase and $1 \mathrm{mM}$-tyramine. The production of $\mathrm{H}_{2} \mathrm{O}_{2}$ and, consequently, of resorufin was quantified at $37{ }^{\circ} \mathrm{C}$ in a Multi-Detection microplate fluorescence reader (FLX800) based on the fluorescence generated (excitation, $545 \mathrm{~nm}$, emission, 590 $\mathrm{nm}$ ) over a 15 min period, during which the fluorescence increased linearly.

Control experiments were carried out simultaneously by replacing the test drugs (new compounds and reference inhibitors) with appropriate dilutions of the vehicles. In addition, the possible capacity of the above test drugs to modify the fluorescence generated in the reaction mixture due to non-enzymatic inhibition was determined by adding these drugs to solutions containing only the Amplex Red reagent in a sodium phosphate buffer.

To determine the kinetic parameters of hMAO-A and hMAO-B $\left(\mathrm{K}_{\mathrm{m}}\right.$ and $\left.\mathrm{V}_{\max }\right)$, the corresponding enzymatic activity of both isoforms was evaluated (under the experimental conditions described above) in the presence of a number of $p$-tyramine concentrations. 
The specific fluorescence emission (used to obtain the final results) was calculated after subtraction of the background activity, which was determined from vials containing all components except the MAO isoforms, which were replaced by a sodium phosphate buffer solution.

Acknowledgment. We are grateful to the Spanish Ministerio de Sanidad y Consumo (PI061457 and PI061537) and to Xunta da Galicia (BTF20303PR, PXIB203022PR and CSA019203PR) and Fondazione Banco Sardegna (Italy) for financial support. M.J.M. also thanks MIUR for a PhD grant.

\section{References}

\footnotetext{
${ }^{1}$ Borges, F.; Roleira, F.; Milhazes, N.; Santana, L.; Uriarte, E. Curr. Med. Chem., 2005, 12, 887.

${ }^{2}$ Hoult, J. R. S.; Payá, M. Gen. Pharmacol., 1996, 27, 713.

${ }^{3}$ Kontogiorgis, C.; Hadjipavlou-Litina, D. J. Enzyme Inhib. Med. Chem., 2003, 18, 63.

${ }^{4}$ Kabeya, L.; Marchi, A.; Kanashiro, A.; Lopes, N.; Silva, C.; Pupo, M.; Lucisano-Valim, Y. Bioorg. Med. Chem., 2007, 15, 1516.

${ }^{5}$ Carotti, A.; Altomare, C.; Catto, M.; Gnerre, C.; Summo, L.; De Marco, A.; Rose, S.; Jenner, P.; Testa, B. Chem. Biod., 2006, 3, 134 .

${ }^{6}$ Chilin, A.; Battistutta, R.; Bortolato, A.; Cozza, G.; Zanatta, S.; Poletto, G.; Mazzorana, M.; Zagotto, G; Uriarte, E.; Guiotto, A.; Pinna, L.; Meggio, Flavio; Moro, S. J. Med. Chem., 2008, 51, 752.

${ }^{7}$ Matos, M.J., Viña, D., Quezada, E., Picciau, C., Delogu, G., Orallo, F., Santana, L., Uriarte, E. Bioorg. Med. Chem. Lett., 2009, 19, 3268.

${ }^{8}$ Matos, M.J., Viña, D., Picciau, C., Orallo, F., Santana, L., Uriarte, E. Bioorg. Med. Chem. Lett., 2009, 19, 5053.

${ }^{9}$ Santana, L.; Uriarte, E.; González-Díaz, H.; Zagotto,G.; Soto-Otero, R.; E. Méndez-Álvarez, E. J. Med. Chem., 2006, 49, 1118.

${ }^{10}$ Santana, L.; González-díaz, H.; Quezada, E.; Uriarte, E.; Yáñez, M.; Viña, D.; Orallo, F. J. Med. Chem., 2008, $51,6740$.

${ }^{11}$ Catto, M.; Nicolotti, O.; Leonetti, F.; Carotti, A.; Favia, A.; Soto-Otero, R.; Méndez-Álvarez, E.; Carotti, A. J. Med. Chem., 2006, 49, 4912.

${ }^{12}$ Gnerre, C.; Catto, M.; Leonetti, F.; Weber, P.; Carrupt, P.; Altomare, C.; Carotti, A.; Testa, B. J. Med. Chem., 2000, 43, 4747.

${ }^{13}$ Chimenti, F.; Secci, D.; Bolasco, A.; Chimenti, P.; Granese, A.; Befani, O.; Turini, P.; Alacaro, S.; Ortuso, F. Bioorg. Med. Chem. Lett., 2004, 14, 3697.

${ }^{14}$ Frémont, L. Life Sci., 2000, 66, 663.
} 
${ }^{15}$ Vilar, S.; Quezada, E.; Santana, L.; Uriarte, E.; Yánez, M.; Fraiz, N.; Alcaide, C.; Cano, E.; Orallo, F. Bioorg. Med. Chem. Lett., 2006, 16, 257.

${ }^{16}$ Orallo, F. In Resveratrol in Health and Disease; Aggarwal, B. B., Shishodia S., Eds.; CRC Press, USA 2005, pp.577.

${ }^{17}$ Leiro, J.; Álvarez, E.; Arranz, J.; Laguna, R.; Uriarte, E.; Orallo, F. J. Leukocyte Biol., 2004, 75, 1156.

${ }^{18}$ Orallo, F. Curr. Med. Chem., 2008, 15, 1887.

${ }^{19}$ De Colibus, L.; Li, M.; Binda, C.; Lustig, A.; Edmondson, D.E.; Mattevi, A. Proc. Natl. Acad. Sci. U.S.A., 2005, 102, 12684.

${ }^{20}$ Binda, C.; Li, M.; Hubalek, F.; Restelli, N.; Edmondson, D.E.; Mattevi, A. Proc. Natl. Acad. Sci. U.S.A., 2003, $100,9750$.

${ }^{21}$ Dostert, P.; Strolin Benedetti, M.; Jafre, M. Monoamine Oxidase: Basic and Clinical Frontiers; Kamijo, K.; Usdin, E.; Nagausu, T., Eds.; Excerpta Medica: Amsterdam, 1982; 197.

${ }^{22}$ Singer, T. P. Muller, F., Ed.; CRC Press: London, 1991; 437.

${ }^{23}$ De Colibus, L.; Li, M., Binda, C.; Lustig, A.; Edmondson, D.E.; Mattevi, A. Proc. Natl. Acad. Sci. U.S.A. 2005, 102, 12684.

${ }^{24}$ Binda, C.; Li, M.; Hubálek, F.; Restelli, N.; Edmondson, D. E.; Mattevi, A. Proc. Natl. Acad. Sci. U. S. A. 2003, 100, 9750.

${ }^{25}$ Yamada,M.; Yasuhara, H. Neurotoxicology 2004, 25, 11.

${ }^{26}$ Rudorfer, M. V.; Potter, V. Z. Drugs 1989, 37, 713.

${ }^{27}$ Palhagen, S.; Heinonen, E.; Hagglund, J.; Kaugesaar, T.; Maki-Ikola, O.; Palm, R. Neurology 2006, 66, 1200.

${ }^{28}$ Guay, D. R. Am. J. Geriatr. Pharmacother. 2006, 4, 330

${ }^{29}$ Riederer, P. Danielczyk, W.; Grunblatt, E. Neurotoxicology 2004, 25, 271.

${ }^{30}$ Youdim, M. B. H.; Fridkin, M.; Zheng, H. J. Neural Transm. 2004, 111, 1455.

${ }^{31}$ Cesura, A. M.; Pletscher, A. Prog. Drug Res. 1992, 38, 171.

32 Determination of human monoamine oxidase (hMAO) isoform activity. The effects of the test compounds on hMAO isoform enzymatic activity were evaluated by a fluorimetric method following the experimental protocol previously described by us. Briefly, $0.1 \mathrm{~mL}$ of sodium phosphate buffer $(0.05 \mathrm{M}, \mathrm{pH} 7.4)$ containing the test drugs in various concentrations and adequate amounts of recombinant hMAO-A or hMAO-B required and adjusted to obtain in our experimental conditions the same reaction velocity [165 pmol of $p$-tyramine/min (hMAO-A: $1.1 \mu \mathrm{g}$ protein; specific activity: $150 \mathrm{nmol}$ of $p$-tyramine oxidized to $p$-hydroxyphenylacetaldehyde/min/mg protein; hMAO-B: $7.5 \mu \mathrm{g}$ protein; specific activity: $22 \mathrm{nmol}$ of $p$-tyramine transformed/min/mg protein)] were placed in the dark fluorimeter chamber and incubated for $15 \mathrm{~min}$ at $37^{\circ} \mathrm{C}$. The reaction was started by adding (final concentrations) $200 \mu \mathrm{M}$ Amplex ${ }^{\circledR}$ Red reagent, $1 \mathrm{U} / \mathrm{mL}$ horseradish peroxidase and $1 \mathrm{mM}$-tyramine. The production of $\mathrm{H}_{2} \mathrm{O}_{2}$ and, consequently, of resorufin was quantified at 37 ${ }^{\circ} \mathrm{C}$ in a multidetection microplate fluorescence reader (FLX800 ${ }^{\mathrm{TM}}$, Bio-Tek ${ }^{\circledR}$ Instruments, Inc., Winooski, VT, USA) based on the fluorescence generated (excitation, $545 \mathrm{~nm}$, emission, $590 \mathrm{~nm}$ ) over a $15 \mathrm{~min}$ period, in which the fluorescence increased linearly.

Control experiments were carried out simultaneously by replacing the test drugs with appropriate dilutions of the vehicles. In addition, the possible capacity of the above test drugs to modify the fluorescence generated in the reaction mixture due to non-enzymatic inhibition (e.g., for directly reacting with Amplex ${ }^{\circledR}$ Red reagent) was determined by adding these drugs to solutions containing only the Amplex ${ }^{\circledR}$ Red reagent in a sodium phosphate buffer. 
The specific fluorescence emission (used to obtain the final results) was calculated after subtraction of the background activity, which was determined from vials containing all components except the hMAO isoforms, which were replaced by a sodium phosphate buffer solution.

On the other hand, in our experiments and under our experimental conditions, the control activity of hMAO-A and hMAO-B (using $p$-tyramine as a common substrate for both isoforms) was $165 \pm 2$ pmol of $p$-tyramine oxidized to $p$ hydroxyphenylacetaldehyde/min $(n=20)$.

${ }^{33}$ All $I C_{50}$ values shown in the table are expressed as means \pm SEM from five experiments.

${ }^{34}$ Hans, N.; Singhi, M.; Sharma, V.; Grover, S.K. Indian J. Chem., Sect B, 1996, 35B, 1159.

${ }^{35}$ Mohanty, S.; Makrandi, J.K.; Grover, S.K. Indian J. Chem., Sect B, 1989, 28B, 766.

${ }^{36}$ Kamat, S.P.; D’Souza, A.M.; Paknikar, S.K.; Beaucahmp, P.S. J. Chem. Research (S), 2002, 242.

${ }^{37}$ Yáñez, M.; Fraiz, N.; Cano, E.; Orallo, F. Biochem. Biophys. Res. Comm. 2006, 344, 688.

${ }^{38}$ Dalla Via, L.; Uriarte, E.; Quezada, E.; Dolmella, A.; M. G. Ferlin, M. G.; Gia, O. Novel Pyrone Side Tetracyclic Psoralen Derivatives: Synthesis and Photobiological Activity. J. Med. Chem. 2003, 46, 3800-3810.

${ }^{39}$ Chimenti, F.; Maccioni, E.; Secci, D.; Bolasco, A.; Chimenti, P.; Granese, A.; Befani, O.; Turini, P.; Alcaro, S.; Ortuso, F; Cirilli, R.; La Torre, F.; Cardia, M. C.; Distinto, S. J. Med. Chem. 2005, 48, 7113-7122. 